Artigo recebido: 30/01/19

Artigo aprovado em: 04/11/19

\title{
FORMAÇÃO DE AGENTES AMBIENTAIS EM DIFERENTES ESPAÇOS PROFISSIONAIS
}

\section{FORMATION OF ENVIRONMENTAL AGENTS IN DIFFERENT PROFESSIONAL SPACES}

\author{
Renan Hohendorff Biagiotto ${ }^{1}$ \\ Maria Antonia Ramos de Azevedo ${ }^{2}$
}

\section{RESUMO}

Diferentes vertentes de Educação Ambiental vêm surgindo, em diferentes espaços educacionais, em diálogo com o arcabouço legal. Nos baseando em material de cunho crítico socioambiental, analisamos 13 artigos científicos da área de Educação Ambiental. Considerando o volume de estudos e diversidade de ferramentas de pesquisas, nos limitamos ao acervo digital da USP para busca e publicações nos últimos 10 anos para um recorte recente. Aponta-se para preponderância nos espaços empresariais e na mentalidade dos cidadãos de práticas tecnicistas; carência de diversidade de espaços não-formais de educação para aplicação de projetos; falta de práticas de Educação Ambiental nos espaços empresariais.

Palavras-chave: Educação Ambiental; Espaço não-formal; Meio Ambiente; Legislação Ambiental.

\section{ABSTRACT}

The interrelation between society and the environment have been shifting, along with the rise of distinct Environmental Education chains, which may be explored in different educational ambiences. We sought support from the laws that results from the evolution of the whole process so far, mixing it with academic studies. We based on 13 articles from the digital collection brought by USP, published within the past 10 years aiming recent material. It's pointed out that in business practices and in the average citizen's mind most ideas and attitudes are related to technical, mechanical and nonthought provoking practices. Furthermore, there is a lack of exploration of non-formal spaces of education.

Keywords: Environmental Education; Non-formal Spaces; Environment; Environmental Law.

\footnotetext{
${ }^{1}$ Mestre em Zoologia pela Universidade Estadual Paulista "Júlio de Mesquita Filho" (Rio Claro) e Especialista em Gerenciamento Ambiental pela Universidade de São Paulo (Esalq). E-mail: hb.renan@hotmail.com

${ }^{2}$ Professora Doutora do Departamento de Educação UNESP/RC. E-mail: maria.antonia@unesp.br
} 


\section{INTRODUÇÃO}

A Educação Ambiental não é tema simples, visto que reúne: opiniões pessoais, decisões políticas, inovações científicas, perspectivas socioambientais e educativas, desenvolvimento econômico, cultura e muito mais. Esta área varia de um simples conjunto de atitudes como separação correta dos resíduos, chegando a englobar questões amplas como desigualdade social e modelos econômico e de desenvolvimento.

Para contextualização, a EA se consolidou como uma ciência, um campo de estudos acadêmicos com profissionais e pesquisadores dedicados. Os profissionais e suas trajetórias de pesquisa com a EA refletem a diversidade de aspectos e o diálogo entre as esferas de conhecimento (REIGOTA, 2007).

O aspecto histórico é uma importante faceta, pois o contexto atual em que tem-se a EA balizada se deve às suas origens. No tangente aos eventos formais, culminantes das tentativas de organização e implementação de agendas ambientalistas internacionais, temos eventos que antecedem a Primeira Guerra Mundial (DIAS et al., 2016: 19-26). Uma síntese cronológica com eventos internacionais relacionados à EA e ao Meio Ambiente está representada pela Figura 1. Os eventos internacionais são capazes de influenciar políticas econômicas e diretrizes educacionais pois propiciam a ocorrência de um contexto favorável à legislação e medidas legais. 


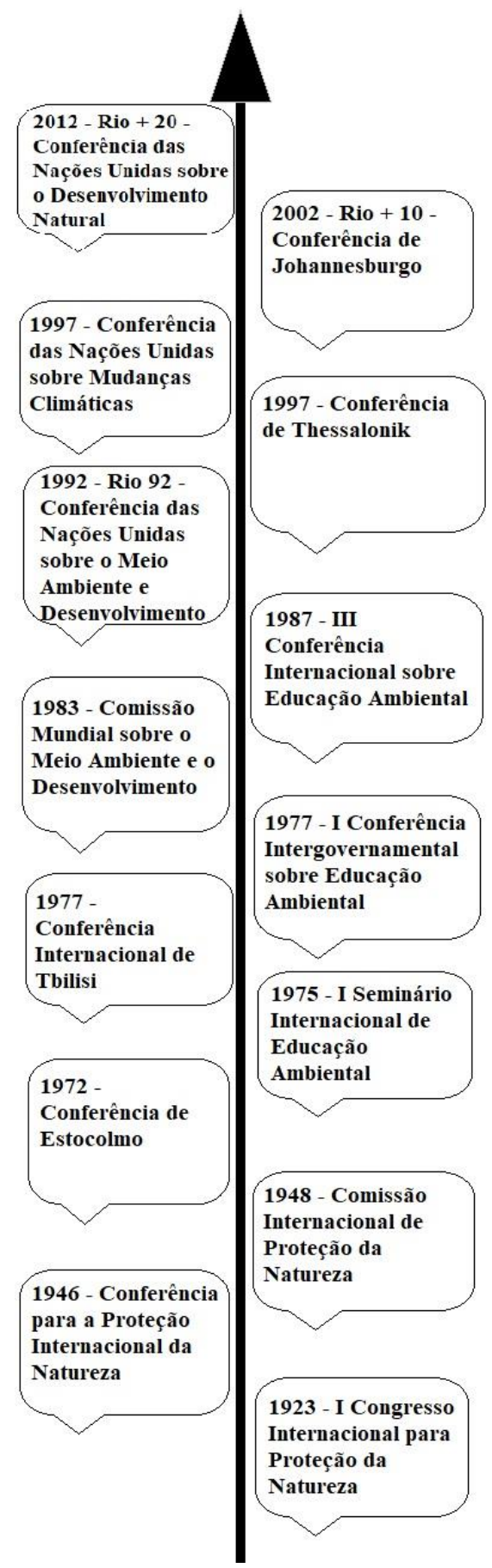

Figura 1. Sequência cronológica de alguns eventos internacionais relacionados à Educação Ambiental e meio ambiente desde 1923 até 2012. Adaptado de Dias et al. (2016: 19-26).

Um marco na consciência ambiental surge na década de 70, principalmente devido à movimentos ecologistas em países do Hemisfério Norte, com questionamentos acerca do perfil educacional e a aplicabilidade da 
ciência, tendo em vistas os fins bélicos e econômicos contestados (REIGOTA, 2012). Portanto, interessa mencionar que de forma "extra-oficial" tem-se a atuação de ONGs e da população civil através de correntes culturais e ideológicas. A emergência da Educação Ambiental como campo científico (uma legitimação como objeto de pesquisa e área do conhecimento) é, também e devido à, atividade dos grupos ativistas.

Atualmente a ciência, a tecnologia, as relações socioambientais e educação estão em transição paradigmática - devido ao acúmulo de questões à serem resolvidas - possível herança do acúmulo de tensões ambientais, sociais, econômicas e culturais que devem ser tratadas em conjunto (RODRIGUES, 2014: 4). Porém, a forma como se trata EA está atualmente equivocada e não atende as necessidades de mudança, revelando a importância para práticas transformadoras e emancipatórias (QUINTAS, 2004).

Este caráter tecnicista possui enfoque em abordagens especificamente técnicas, colocando os processos destacados da interação social (TOZZONIREIS, 2001). Estas abordagens acabam fragmentando o conhecimento, tornando-o praticamente abstrato na vida dos indivíduos e apenas favorecendo a reafirmação de relações centralizadas de poder: aquele que detém o conhecimento (TOZZONI-REIS, 2002).

Ao buscar romper com esse enfoque, pode-se voltar contra as atitudes afirmativas da concentração de poder e marginalização. Desta forma, destacase a importância para múltiplas formas do saber, a cultura como forma de sabedoria (CARVALHO, 1998). São aspectos interdisciplinares, algo essencial da $E A$, visto a sua não-linearidade, um amplo diálogo com vários temas e conhecimentos (TOZZONI-REIS, 2002; JACOBI, 2003; OLIVEIRA, 2010; RODRIGUES et al., 2013).

Para uma melhoria no aspecto ambiental, é necessário reaver um equilíbrio, satisfação e melhoria no aspecto social, fim de uma dicotomia:

"Hoje, estamos tendo a necessidade de legitimar formas de pensamento não lineares, tanto na ciência como na arte e em outras formas de expressão da realidade. Em busca de novas metáforas e narrações para o sentido da vida, há de ousar a dupla ruptura epistemológica, qual seja: a ciência, depois de romper com o senso comum, há de romper com essa primeira ruptura epistemológica a fim de se transformar num novo senso comum. Isso significa que 0 diálogo da ciência com o senso comum transforma o conhecimento 
científico em um senso comum novo e emancipatório, ou em "um conhecimento prudente para uma vida decente".(RODRIGUES, 2014, p. 04).

Portanto, interdisciplinaridade e integração são importantes para uma educação ambiental crítica (TORRES et al., 2014). Como por exemplo a Abordagem Temática Freireana, desenvolvida por Paulo Freire, em diferentes passos para contextualização do conhecimento e maior protagonismo do educando no aprendizado (FREIRE, 2005).

O ambiente propício para inovação é também variado: estamos tratando das possibilidades para locais como a escola, mas também fora dela - é o contexto da educação formal, a educação não-formal e a educação informal (GOHN, 2006: 3).

A educação ambiental encontra espaço para se manifestar de diferentes formas, em suma: a educação formal é aquela que ocorre em instituições oficiais de ensino, com estrutura curricular, organizadas em etapas, como a escola; a educação não-formal é aquela realizada de forma organizada, em instituições extra-oficiais, com frequência estabelecida; a educação informal, por sua vez, é aquela que ocorre em todos os espaços frequentados pelo indivíduo (casa, rua, clube, mercados, etc) caracterizando a transferência de conhecimentos constante e permanente (GOHN, 2006).

A educação não-formal possui característica possibilidade de inclusão social, múltipla interação mediante formação política de cidadãos, flexibilidade dentro de uma ética e condutas socialmente aceitáveis (GHON, 2006; 2009: 4). A diversidade de formas de atuação e pluralidade de ambientes propícios para a prática deve ser observada (JACOBI, 2003), assim como o arcabouço legal que a fundamenta, regula e contextualiza.

O arcabouço legal nacional voltado ao ambiente e à educação representa possibilidade de inovação. Partindo de uma definição de meio ambiente generalista dada pela Política Nacional de Meio Ambiente, Lei no 6.938/1981, Art. 3, inciso I, temos que o meio ambiente é o conjunto de condições, leis, influências e interações de ordem física, química e biológica (BRASIL, 1981). 
À esta definição temos o preconizado pela Constituição Federal, Art. 225, atribuindo o meio ambiente ecologicamente equilibrado como direito de todos, cabendo ao Poder Público defende-lo, preservá-lo, entre outros (BRASIL, 1988).

A Constituição Federal traz como competência das esferas de administração pública (Municipal, Estadual e Federal) a proteção e preservação do meio ambiente, Art. 23, incisos VI e VII. Soma-se, ainda, o princípio de asseguração de uma existência digna, contemplando a justiça social, observando o princípio da defesa do meio, previsto no Art. 170 (BRASIL, 1988).

Aspectos básicos na legislação subsidiam uma abordagem socioambiental. A Política Nacional do Meio Ambiente, Art. 2, aponta para melhoria e recuperação da qualidade ambiental para condições de desenvolvimento socioeconômico, segurança e proteção à dignidade da vida humana. O Poder Público deverá, entre outras medidas, atingir este objetivo através da $E A$ - conforme o inciso $X$ - ao principiar acesso a todos os níveis de ensino, e à comunidade (BRASIL, 1981).

Resgatando novamente a Constituição Federal, Art. 24, inciso IX e Art. 205, temos que compete ao Poder Público o estímulo ao ensino, à cultura e à educação, cuja promoção e incentivo devem compreender o desenvolvimento pessoal para o exercício da cidadania. Sob esta ótica, acresce o predisposto pelo Art. 206, em seus incisos II e III:

"Art. 206. O ensino será ministrado com base nos seguintes princípios:

II - liberdade de aprender, ensinar, pesquisar e divulgar 0 pensamento, a arte e o saber;

III - pluralismo de ideias e de concepções pedagógicas, e coexistência de instituições públicas e privadas de ensino;" (BRASIL, 1988).

A Política Nacional do Meio Ambiente legitima como instrumento, para tais objetivos, o processo de licenciamento ambiental para atividades efetiva ou potencialmente poluidoras. Ou seja, projetos de educação e/ou capacitação de funcionários são requisitos para o licenciamento do empreendimento. 
Este é o ponto de ligação entre as atividades realizadas pelos empreendedores e a cobrança do Poder Público por atividades educativas. $\mathrm{O}$ Art. 3 da Política Nacional de EA, instrui que esta é direito de todos e é função do Poder Público a promoção de políticas que a tratem de forma articulada, dentro e fora das escolas (BRASIL, 1999).

O Decreto 4.281/2002, que regulamenta a Política Nacional de EA, instrui que tal política deverá ser executada pelos órgãos integrantes do SISNAMA. Para a sua execução, devem os órgãos criar e manter programas de educação integrados às atividades de conservação da biodiversidade e ao licenciamento ambiental (BRASIL, 2002).

A Política Nacional de EA, Art. 1, a coloca como: o conjunto de processos através dos quais o indivíduo e a coletividade constroem e praticam valores sociais, habilidades, atitudes e competências para a conservação, para a qualidade de vida e sustentabilidade ambiental. Este referido conjunto de processos, valores, habilidades e atitudes é um componente essencial e permanente na educação nacional, devendo estar presente em todos os níveis e modalidades (BRASIL, 1999).

Os objetivos fundamentais, elencados no Art. 5, encontram-se alinhados, sendo o seu exercício pautado em metas e exigências que podem e devem ser cumpridas nos espaços não-formais de educação. Estes contemplam: uma compreensão integrada do meio ambiente e suas complexas relações (aspectos multifacetados); o estímulo e fortalecimento de uma consciência crítica sobre a problemática socioambiental; o incentivo à participação individual e coletiva. A EA nos espaços não-formais de educação representa, neste sentido, todo o conjunto e práticas educativas voltadas à sensibilização da coletividade, conforme o Art. 13 (BRASIL, 1999).

Como um aspecto complementar, tem-se as perspectivas da Resolução CNE/CP 2/2012 do MEC. Conforme o Art. 2, a EA é uma dimensão da educação, uma atividade intencional da prática social que imprime no desenvolvimento individual um caráter social na relação natureza e homem (BRASIL, 2012). Já no Art. 3, temos que a EA visa construção de conhecimentos, habilidades, atitudes e valores voltados aos cuidados com a 
vida, justiça e equidade socioambiental, proteção do meio natural e construído. Portanto, de acordo com os Art. 5 e Art. 6, esta dimensão da educação não é neutra e envolve valores, interesses e visões (BRASIL, 2012).

\section{MATERIAIS E MÉTODOS}

Muitos periódicos abordam educação e meio ambiente, mesmo sob enfoque da situação brasileira sob a luz de legislação nacional. Viabilizando a revisão bibliográfica, foram focados periódicos publicados dentro dos últimos 10 anos.

O presente estudo faz uso de uma abordagem de cunho qualitativo, sendo uma revisão bibliográfica de estudos científicos nas áreas de ciências naturais e humanas. A análise interpretativa e suas premissas são um método que, assim como em todo estudo, estão sujeitos à intuição do cientista (ALVES-MAZZOTTI \& GEWANDSZNAJDER, 2001: 04).

Este estudo contempla 13 artigos selecionados. Para a pesquisa, foi utilizado o Sistema Integrado de Bibliotecas da Universidade de São Paulo (SIBiUSP), trazendo artigos publicados em diferentes periódicos. O SIBiUSP, cujo regimento é dado pela Resolução USP № 5776, de 17 de agosto de 2009, objetiva o subsídio e fornecimento de condições para o funcionamento sistêmico das bibliotecas da USP. Portanto, a busca por artigos em periódicos foi feita no acervo das bibliotecas da instituição, utilizando-se do crivo originário das palavras-chave e do ano de publicação.

O total de obras encontradas com as palavras-chave utilizadas variou de 255 a 8.653 de acordo com a palavra-chave utilizada. A pesquisa foi feita com as palavras-chave exatamente como se segue: Educação Ambiental; Educação Ambiental Empresarial; Educação Ambiental Corporativa; Espaço Não-formal; Plano de educação ambiental. 


\section{RESULTADOS}

Os artigos que apresentaram a intersecção de todos esses temas e estas palavras-chave foram cuidadosamente analisados, um sumário das informações gerais estão no Quadro 1.

Quadro 1. Autores, título, ano e periódico das publicações analisadas.

\begin{tabular}{|c|c|c|c|}
\hline AUTOR (ES) & TÍTULO & ANO & PERIÓDICO \\
\hline $\begin{array}{l}\text { JACOBI, P. R.; } \\
\text { TRISTÃO, M.; } \\
\text { FRANCO, M. I. G. } \\
\text { C. }\end{array}$ & $\begin{array}{c}\text { A Função Social da } \\
\text { Educação Ambiental nas } \\
\text { Práticas Colaborativas: } \\
\text { Participação e Engajamento }\end{array}$ & 2009 & $\begin{array}{l}\text { Centro de } \\
\text { Estudos } \\
\text { Educação e } \\
\text { Sociedade }\end{array}$ \\
\hline BAGNOLO, C. M. & $\begin{array}{c}\text { Empresariado e Ambiente: } \\
\text { Algumas Considerações } \\
\text { sobre a Educação Ambiental } \\
\text { no Espaço Escolar }\end{array}$ & 2010 & $\begin{array}{c}\text { Revista Ciência } \\
\text { \& Educação }\end{array}$ \\
\hline $\begin{array}{l}\text { MORAIS, C. F.; } \\
\text { COLESANTI, M. }\end{array}$ & $\begin{array}{l}\text { Uma Proposta para Coleta } \\
\text { Seletiva: Implantando a } \\
\text { Educação Ambienal na } \\
\text { Empresa Schincariol - } \\
\text { Uberlândia/MG }\end{array}$ & 2011 & $\begin{array}{c}\text { Caminhos de } \\
\text { Geografia }\end{array}$ \\
\hline $\begin{array}{c}\text { FRIGO, J. P.; } \\
\text { SILVEIRA, D. S. }\end{array}$ & $\begin{array}{c}\text { Educação Ambiental e } \\
\text { Construção Civil: Práticas de } \\
\text { Gestão de Resíduos em Foz } \\
\text { do Iguaçu - PR }\end{array}$ & 2012 & $\begin{array}{c}\text { Revista } \\
\text { Monografias } \\
\text { Ambientais }\end{array}$ \\
\hline $\begin{array}{c}\text { NEVES, E. B.; } \\
\text { PICONCELLI, M. C. } \\
\text { A.; OLIVEIRA, S. H. } \\
\text { K.; ROZEMBERG, } \\
\text { B. }\end{array}$ & $\begin{array}{c}\text { Práticas de Educação } \\
\text { Ambiental: Breve Diagnóstico } \\
\text { em Organizações Militares no } \\
\text { Exército Brasileiro }\end{array}$ & 2012 & $\begin{array}{c}\text { Revista Ciência } \\
\text { \& Educação }\end{array}$ \\
\hline
\end{tabular}




\begin{tabular}{|c|c|c|c|}
\hline $\begin{array}{c}\text { MENDONÇA, M. G.; } \\
\text { COLESANTI, M. T. } \\
\text { M. }\end{array}$ & $\begin{array}{c}\text { Reflexões Sobre Teoria e } \\
\text { Prática em Educação } \\
\text { Ambiental: Estudo de Caso } \\
\text { na Percepção Ambiental da } \\
\text { População do Município de } \\
\text { Uberlândia (MG) }\end{array}$ & 2015 & $\begin{array}{c}\text { Caminhos de } \\
\text { Geografia }\end{array}$ \\
\hline $\begin{array}{l}\text { SILVA, V. A.; } \\
\text { JESUS, M. J. F.; } \\
\text { MORIGI, J. B.; } \\
\text { SOUZA, A. D. }\end{array}$ & $\begin{array}{c}\text { Práticas de Sustentabilidade } \\
\text { na Gestão da Empresa } \\
\text { Cristófoli Equipamentos de } \\
\text { Biossegurança, Situada no } \\
\text { Município de Campo Mourão, } \\
\text { Paraná, Brasil }\end{array}$ & 2015 & $\begin{array}{c}\text { Revista de } \\
\text { Administração, } \\
\text { Contabilidade e } \\
\text { Economia }\end{array}$ \\
\hline $\begin{array}{l}\text { NETO, G. C. O.; } \\
\text { FILHO, M. G.; } \\
\text { GANGA, G. M. D.; } \\
\text { NAAS, I. A.; } \\
\text { VENDRAMETTO, } \\
\text { O. }\end{array}$ & $\begin{array}{l}\text { Princípios e Ferramentas da } \\
\text { Produção Mais Limpa: um } \\
\text { Esstudo Exploratório em } \\
\text { Empresas Brasileiras }\end{array}$ & 2015 & $\begin{array}{l}\text { Gestão e } \\
\text { Produção }\end{array}$ \\
\hline $\begin{array}{c}\text { COSTA, J. M.; } \\
\text { REZENDE, J. F. D. }\end{array}$ & $\begin{array}{c}\text { Aprendizagem } \\
\text { Organizacional e } \\
\text { Sustentabilidade Ambiental: } \\
\text { um Estudo com as Empresas } \\
\text { Associadas à REDEPETRO - } \\
\text { RN }\end{array}$ & 2015 & $\begin{array}{c}\text { Revista } \\
\text { Eletrônica } \\
\text { Gestão \& } \\
\text { Sociedade }\end{array}$ \\
\hline $\begin{array}{l}\text { KONFLANZ, T.; } \\
\text { FREITAS, N. }\end{array}$ & $\begin{array}{l}\text { A Educação Ambiental } \\
\text { Inserida no Licenciamento }\end{array}$ & 2015 & $\begin{array}{c}\text { Revista } \\
\text { Monografias } \\
\text { Ambientais }\end{array}$ \\
\hline $\begin{array}{l}\text { CASSOL, A.; } \\
\text { CINTRA, R. F.; } \\
\text { LUZ, J. }\end{array}$ & $\begin{array}{l}\text { A Responsabilidade Social } \\
\text { Corporativa e as Práticas de } \\
\text { Gestão do Capital Intelectual } \\
\text { Divulgadas por Empresas do } \\
\text { Setor de Papel e Celulose }\end{array}$ & 2017 & $\begin{array}{c}\text { Revista de } \\
\text { Gestão } \\
\text { Ambiental e } \\
\text { Sustentabilidade }\end{array}$ \\
\hline
\end{tabular}




\begin{tabular}{|c|c|c|c|}
\hline $\begin{array}{l}\text { MACHADO, S. M. } \\
\text { F.; LOUREIRO, C.; } \\
\text { LEITE, R. R.; } \\
\text { BRITO, T. S. A.; } \\
\text { VASCONCELOS, F. } \\
\text { C. W. }\end{array}$ & $\begin{array}{c}\text { Educação Ambiental no } \\
\text { Processo de Licenciamento }\end{array}$ & 2018 & $\begin{array}{c}\text { Educação } \\
\text { Ambiental em } \\
\text { Ação }\end{array}$ \\
\hline $\begin{array}{c}\text { FARIA, J. S.; } \\
\text { PINTO, V. P. S. }\end{array}$ & $\begin{array}{l}\text { A Educação Ambiental no } \\
\text { Licenciamento Ambiental: } \\
\text { Reflexões Teóricas e } \\
\text { Metodológicas Pertinentes }\end{array}$ & 2018 & $\begin{array}{c}\text { Educação } \\
\text { Ambiental em } \\
\text { Ação }\end{array}$ \\
\hline
\end{tabular}

"A Função Social da Educação Ambiental nas Práticas Colaborativas: Participação e Engajamento" (JACOBI et al., 2009):

Apontando a crise estrutural ampla que estamos, os autores indicam a uma mudança paradigmática, uma crise epistemológica, indo ao encontro de um amplo senso de uma crise ambiental. Neste sentido, a ampla participação ativa da sociedade para identificação de problemas e soluções é a temática trabalhada.

A aplicação destas atitudes, conforme proposta no trabalho, é a projeção da EA escolar em conjunto com o público e o espaço não-formal, a articulação de processos democráticos participativos escolares com outras instituições e movimentos sociais. Jacobi et al. (2009) discutem um saber e fazer coletivo, unindo o espaço formal e o não-formal de educação ambiental para promoção de intervenções na realidade local.

"Empresariado e Ambiente: Algumas Considerações sobre a Educação Ambiental no Espaço Escolar" (BAGNOLO, 2010):

Há consideração da educação ambiental corporativa e empresarial em uma perspectiva escolar. Bagnolo (2010) retrata a percepção do empresariado na insuficiência da concepção de um produto ecológico e o emprego de tecnologias limpas sem que exista o comprometimento de trabalhadores conscientes com a preservação ambiental. Portanto, trata-se a função que 0 
empresariado pode desenvolver ao trazer para o ambiente escolar o âmbito da EA empresarial.

Um dos fatores de destaque é o conceito de responsabilidade social, uma demanda para a imagem empresarial. Não obstante, há também a parceria público-privada do empresariado para com a escola pública, incentivada pela ideologia do neoliberalismo (BAGNOLO, 2010). Bagnolo (2010), atesta para um caminho preocupante do perfil da EA no país, visto que muitas práticas ambientais realizadas podem carecer de um perfil crítico, além de desqualificar projetos públicos através de uma gradual substituição dos protagonistas dos processos.

"Uma Proposta para Coleta Seletiva: Implantando a Educação Ambiental na Empresa Schincariol - Uberlândia/MG" (MORAIS \& COLESANTI, 2011):

Abordando o processo de gerenciamento de resíduos sólidos e práticas de EA da empresa em questão, ao procurar uma certificação de comércio, a certificação ambiental possui diferentes implicações positivas (MORAIS \& COLESANTI, 2011). Em um sentido percebe-se a importância do fazer notar o interesse de um indivíduo ou corporação para os demais. Por outro lado, é pertinente a busca por maneiras de se alinhar o discurso às práticas.

A Educação Ambiental para uma sociedade mais justa pode ser trabalhada de formas alternativas, explorada como treinamento à grupos de funcionários (MORAIS \& COLESANTI, 2011). Os treinamentos foram feitos através de um ciclo de palestras, seguido pela implantação prática dos locais para realização da coleta seletiva.

"Educação Ambiental e Construção Civil: Práticas de Gestão de Resíduos em Foz do Iguaçu - PR " (FRIGO \& SILVEIRA, 2012):

Neste trabalho, Frigo \& Silveira (2012) exploram a elaboração de um panfleto informativo com linguagem acessível para a ampla distribuição e organização de fácil entendimento para os funcionários da construção civil. As visitas por locais problemáticos e a exposição do descarte ilegal, com confecção de folheto informativo, sensibilizou o corpo de funcionários das obras-alvo. 
"Práticas de Educação Ambiental: Breve Diagnóstico em Organizações Militares do Exército Brasileiro" (NEVES et al., 2012):

Neste estudo, 52 unidades do Exército Brasileiro foram avaliadas de forma qualitativa através de questionários, afim de identificar se há e como é a EA. A preocupação com as questões ambientais não deveria passar desapercebida, devido a formação de muitos oficiais, dispêndio de equipamentos, aspectos operacionais, entre outros.

As práticas vigentes na instituição, como inspeções regulares por chefias, atividades de rotina e treinamentos podem favorecer a gestão ambiental, no caso da existência desta mentalidade e cumprimento de normas. Entretanto, o trabalho indica a existência preponderante de EA com ações pontuais e mecânicas, como plantio de mudas e palestras (NEVES et al., 2012).

"Reflexões Sobre Teoria e Prática em Educação Ambiental: Estudo de Caso da Percepção Ambiental da População do Município de Uberlândia (MG)" (MENDONÇA \& COLESANTI, 2015):

Os autores apontam para um panorama geral de programas e ações ambientais desconectadas. Neste sentido, Mendonça \& Colesanti (2015) trazem à discussão a importância de referenciais teóricos para divulgação das ações de caráter educativo, para preservação e melhoria da qualidade ambiental; uma forma de divulgação das atitudes necessárias.

A noção de responsabilidade socioambiental da população amostrada é trabalhada, contatando-se a existência de uma visão relativamente crítica do cidadão. No entanto, valores como $45 \%$ dos entrevistados atribuírem as responsabilidades ambientais à terceiros; apenas 19,5\% já participaram em atitude voltada preservação ambiental (MENDONÇA \& COLESANTI, 2015). Neste caso, os autores acreditam em uma falha das instituições municipais em conscientizar os munícipes através da produção e divulgação de informações.

"Práticas de Sustentabilidade na Gestão da Empresa Cristófoli Equipamentos de Biossegurança, Situada no Município de Campo Mourão, Paraná, Brasil" (SILVA et al., 2015): 
Objetivando uma imagem mais ecologicamente sustentável, e de maior responsabilidade social, a empresa originou o Programa Mil Árvores para o reflorestamento de uma microbacia e educação ambiental. A responsabilidade social corporativa, gestão ambiental e sustentabilidade são os pilares para discussão, que sob a ótica empresarial, podem representar desejável imagem (SILVA et al. 2015).

"Princípios e Ferramentas da Produção Mais Limpa: um Estudo Exploratório em Empresas Brasileiras" (NETO et a., 2015):

A adoção de práticas de produção mais limpa é fruto da absorção de procedimentos para redução de desperdícios, atendimento às normas ambientais e o tratamento de resíduos. Os princípios e ferramentas avaliados nas empresas amostradas são diversos; interessa o fato apurado de $68 \%$ a $80 \%$ das empresas brasileiras pesquisadas adotarem a integração do planejamento e controle junto a Educação Ambiental (NETO et a., 2015).

A parcela de $80 \%$ das 102 empresas investigadas visa estabelecer um sistema de produção mais limpa. Índices mostram que os aspectos de investimento em treinamentos, certificação de insumos e tecnologias apropriadas possuem importante função para indicar o repasse no preço do produto ou redução de lucratividade (NETO et a., 2015).

"Aprendizagem Organizacional e Sustentabilidade Ambiental: Um Estudo com as Empresas Associadas à REDEPETRO - RN" (COSTA \& REZENDE, 2015):

A sustentabilidade das empresas mediante práticas organizacionais foi enfocada e, conforme apontado, a principal causa para envolvimento com a melhoria das práticas institucionais é de ordem financeira. As dificuldades estão atreladas à falta de tempo e o nível de instrução dos funcionários.

Aspectos pertinentes de comunicação foram averiguados, no caso os murais (um meio não digital); o repasse de técnicas e conceitos é feito majoritariamente por treinamentos, avaliações e controles feitos por consultorias e reuniões (COSTA \& REZENDE, 2015).

"A Educação Ambiental Inserida no Licenciamento" (KONFLANZ \& FREITAS, 2015): 
Segundo os autores, a EA no processo de licenciamento é importante, este apresenta por natureza a característica de aproximar o empreendimento em todas as suas concepções ao Poder Público, de forma ordenada e disciplinada conforme a legislação, sendo a EA uma maneira de melhorar e aproveitar este processo (KONFLANZ \& FREITAS, 2015). Conforme consta, a EA ganhou crescente relevância no licenciamento e na gestão, por sua importância na socialização de informações e disseminação de conhecimentos, dentre os variados motivos, sua implementação é prevista na legislação em todos os níveis.

"A Responsabilidade Social Corporativa e as Práticas de Gestão do Capital Intelectual Divulgadas por Empresas do Setor de Papel e Celulose" (CASSOL et al., 2017):

O estudo é voltado para o conceito de Capital Intelectual e dialoga com o presente estudo ao evidenciar práticas envolvidas com a fomentação do desenvolvimento e formação pessoal, levando a investimentos também em sistemas; inovações de produtos e processos; ativos. Como indicado pelos autores, a responsabilidade social é também uma base para mudanças sociais que pode originar-se com a preocupação da própria autoimagem empresarial ou, talvez menos frequentemente, da atuação além do interesse próprio (CASSOL et al., 2017).

"Educação Ambiental no Processo de Licenciamento" (MACHADO et al., 2018):

Trabalhando a Educação Ambiental em espaços formais de educação, dentro do escopo do licenciamento ambiental, é também uma pesquisa de revisão bibliográfica. A análise crítica da legislação e das práticas torna interessante que apesar de majoritariamente abordada como uma forma de compensação dos impactos causados, a EA deveria ser uma medida educacional efetiva para melhorias na qualidade de vida local (MACHADO et al., 2018).

"A Educação Ambiental no Licenciamento Ambiental: Reflexões Teóricas e Metodológicas Pertinentes" (FARIA \& PINTO, 2018): 
Mais uma revisão bibliográfica, o artigo enfoca a articulação de perspectivas teóricas e metodologias práticas para inclusão da EA nos licenciamentos ambientais. Com uma especial ênfase, os autores colocam a perspectiva crítica da educação como mais adequada e significativa nos processos de licenciamento, levando-se em consideração as demandas socioambientais (FARIA \& PINTO, 2018). Especial atenção a importância da consideração dos grupos prioritários no processo educativo (LOUREIRO, 2009; FARIA \& PINTO, 2018).

Ao explorar as vertentes intituladas como a conservadora e a crítica, os autores se aprofundam na segunda. A abordagem crítica vem a se contrapor à conservadora, pois esta é, em suma, uma forma "desintegrada, fragmentada, reduzida, individualista, comportamentalista, simplista, unilateral, ou seja, que desconsidera a diversidade existente na relação entre homem e natureza e a complexidade do cotidiano" (FARIA \& PINTO, 2018).

Existem três grandes itens que sumarizam a abordagem analítica do conteúdo que foi exposto acima, sendo: o conceito de EA; a EA não-formal apontada, sua concepção e práticas; o papel educativo da EA nas empresas.

\section{DISCUSSÃO}

A EA e suas vertentes variam grandemente conforme o autor e até mesmo o ano da publicação, tomando duas grandes vertentes, conforme Tozzoni-Reis (2001; 2002): a EA científica e/ou tecnicista, voltada a práticas individuais; relacionada ao aspecto naturalista, índices, processos e procedimentos. Neste sentido, carecendo de um questionamento, investigações e esclarecimentos de ordem social que vêm a passar desapercebidos.

A outra vertente é referida como crítica, voltada ao aspecto socioeconômico que não necessariamente vem a excluir a ampla importância do conhecimento técnico ambiental, no entanto irá contextualizá-lo. À esta breve exemplifica-se com o que coloca Paulo Freire (FREIRE, 2005) em sua metodologia proposta: é necessário que o indivíduo se aproprie dos 
conhecimentos em seu contexto e, através de sua óptica, trabalhar os temas pertinentes sua realidade.

Jacobi et al (2009) se alinha ao colocado como referencial para EA, pautando em questões importantes a nível de comunidade e, consequentemente, globais. Esta está atribuída a cidadania, ao salvaguardar aspectos diretamente ligados a qualidade de vida, saúde, cultura (BRASIL, 1999). A articulação entre EA e comunidade, englobando escolas e movimentos sociais, possui potencial para promoção da almejada abordagem socioeconômica e ambiental, colocando jovens em contato com embates realistas (JACOBI et al., 2009).

Os espaços formais e não-formais podem ser explorados neste cenário. A utilização destes espaços, sugerida por Jacobi et al (2009), está de acordo com a Lei no 6.938/1981 (BRASIL, 1981) e com as possibilidades indicadas por Gohn (2006).

A diferença entre as vertentes de EA podem ser tênues, porém é importante a vinculação de produtos ecológicos e trabalhadores engajados nas questões ambientais (BAGNOLO, 2010). No entanto, como também é apontado pelo autor, as formas de engajamento e sua origem podem tornar-se um viés. Bagnolo (2010) neste sentido explora a temática da EA empresarial, prevista em lei, porém no espaço escolar.

Como levantado no referencial a partir de Quintas (2004) e de Rodrigues (2014), práticas promovidas como visitas escolares às instalações das empresas, a promoção do trabalho técnico realizado pode ser uma forma de marketing travestido de EA, tecnicista e mercadológico. Apesar de ter seus benefícios, há de se atentar para a possibilidade de uma parceria entre escolas e empresas que não leve a uma tomada de consciência questionadora.

Os espaços formais e os espaços não-formais de educação podem estar situados em instituições públicas e privadas (BRASIL, 1999). Neves et al. (2012) em seu estudo traz a investigação interessante nas instituições do Exército Brasileiro, nas quais a EA é promovida em ações pontuais voltadas ao meio ambiente, como plantio de mudas, palestras eventuais e treinamentos. 
Como trata Jacobi (2003), a EA deve ser constante e promover ações voltadas a melhoria da qualidade de vida aliada à preservação do meio ambiente.

Entretanto, Neves et al (2012) endossa a adoção de práticas de EA superficiais nestes quesitos, tratando-se daquelas padronizadas atitudes pontuais: lições acerca da separação adequada de resíduos, plantio de mudas e etc, sua frequência também não está alinhada com o perfil crítico de contextualização (TOZZONI-REIS, 2001).

A crítica feita por Neves et al (2012) e a apreensão de Bagnolo (2010) são retificadas por Machado et al (2018) ao aprofundar-se no emprego da EA no processo de licenciamento ambiental. A EA é uma ferramenta prevista por lei e implementada junto ao licenciamento. Desta forma, Machado et al (2018) entendem que a EA deveria ser tratada como ferramenta de melhoria da qualidade de vida social, englobando a participação do empreendedor e sua responsabilidade sobre os impactos causados pelo seu respectivo empreendimento.

É, como destacam os autores, uma ferramenta voltada à mitigação ou prevenção dos impactos. A EA crítica segue representada por Faria \& Pinto (2018) seguindo a mesma linha de raciocínio de Machado et al (2018), em importante consideração aos grupos prioritários e as suas demandas socioambientais identificadas.

O que se desenha, portanto, é uma educação com suas funções organicamente articuladas, garantindo a apropriação dos estudos técnicos, em espaços próprios, pelos agentes envolvidos (FARIA \& PINTO, 2018). Tornando-se assim os envolvidos capazes de maior autonomia de decisão (QUINTAS, 2004).

Os desafios, por outro lado, podem aparecer de formas diversas. $O$ fomento técnico e comprometimento ético com a EA no processo de licenciamento; participação dos envolvidos no processo em sua dimensão política, articulação teórica e prática (FARIA \& PINTO, 2018); o desafio em ressignificar a posição da EA no processo de licenciamento (MACHADO et al., 2018). Esta ressignificação e seu papel, atualmente, consistem em uma forma amena de compensação atribuída a EA, na forma de cartilhas, folders e 
palestras realizadas a população e empregados: o que confere uma efetividade baixa, engajada como paliativo (MACHADO et al., 2018). Portanto, a comunidade acaba às margens do que realmente acontece, sem 0 posicionamento a respeito das tomadas de decisão.

Dentre uma EA crítica e uma tecnicista, ao menos coloca-se o ambiente em evidência. A propagação de temas e métodos ligados ao meio ambiente tem seu valor, levando possivelmente a estratégias que podem se somar aos esforços da EA (FRIGO \& SILVEIRA, 2012). A contemplação por parte do empreendedor de sua responsabilidade com treinamentos e noções relacionadas ao meio ambiente junto ao corpo de funcionários pode abrir novas portas.

A conformidade legal é claramente de suma importância, porém não garante uma resposta à altura da crise paradigmática vigente. A EA pode ir além e tornar-se, mediante o licenciamento ambiental, uma ferramenta efetiva para mudanças (KONFLANZ \& FREITAS, 2015). Não se faz um licenciamento ambiental ético, correto com a responsabilidade social apenas com técnicas (CARVALHO, 1998).

Alguns pesquisadores se adentram no campo da responsabilidade social exercida pelas empresas com seus funcionários em temas específicos, como é o caso de Cassol et al. (2017). Como constatado, muitas empresas chegam a veicular práticas de valorização e formação internas. Mesmo que eventualmente não estejam implementadas como se sugere, Cassol et al. (2017) chama atenção para um aspecto: este tema colocado em pauta pelas corporações já confere certa visibilidade ao tema.

Empresas do ramo de papel e celulose, avaliadas pelos autores, possuem diferentes sistemas de investimentos do que se denomina capital intelectual e responsabilidade social corporativa (CASSOL et al., 2017). Tangem a formação de pessoal, capacitação, tanto do setor operacional como a gerência e até mesmo os clientes.

Este é um tema importante cunhado pela Lei no 12.305/2010 (BRASIL, 2010), o qual encontra-se contemplado por empresas que invistam em sistemas de inovação de produtos e processos, cobrando de fornecedores o 
mesmo; promove melhorias à capacitação dos envolvidos. Além destes refinamentos, a responsabilidade social corporativa pode agregar valor a imagem da empresa (CASSOL et al., 2017).

A iniciativa privada pode contar também com incentivos provenientes de certificações, visando um retorno financeiro e uma boa imagem. Estes são aspectos secundários no presente estudo, porém além da legislação, organizações e consumidores podem se tornar forças motivadoras para tais implementações como consumidores críticos (MORAIS \& COLESANTI, 2011). Apesar de um incentivo mercadológico, a certificação ambiental pode promover um trabalho de reflexão.

Porém, não seria esta uma faceta da EA que, apesar de um cunho menos crítico, pode contribuir com a preservação do meio ambiente e transformação social? Cabe aos envolvidos conferir a tônica do pensamento crítico, pois as práticas podem ter um perfil conservador ou crítico (RODRIGUES, 2014).

Outro exemplo de interação entre o meio empresarial, funcionários e comunidade é tratado por Silva et al. (2015) e se refere a Cristófoli Equipamentos de Segurança. Este estudo aponta para uma ligação entre os três eixos de análise promovidos pelo presente trabalho (EA crítica, EA em espaços não-formais de educação e EA promovidas por empresas), em um projeto de reflorestamento (SILVA et al., 2015).

O plantio acompanha o monitoramento do local, trilhas ecológicas com placas informativas e atividades de EA no local. Esta iniciativa possui um grande potencial para exploração de conceitos de EA, aliada a restauração do meio ambiente e valorização da área (SILVA et al., 2015).

A EA, como apontado por Neto et al. (2015), também possui sua função para melhorias de performances. O empresariado brasileiro pode se utilizar de EA para variados fins, como a disseminação de boas práticas para 0 acondicionamento e tratamento de resíduos e atingir um patamar de produção mais limpa - em conformidade com a Lei no 6.938/1981 (BRASIL, 1981). Neto et al. (2015) também nos mostra uma importante característica da EA em uma 
revisão de processos, amparada por legislação específica, objetivando desenvolvimento de insumos mais adequados, cadeia produtiva mais limpa.

Não se trata apenas do entendimento e aplicações de EA que podem representar limitações ou desvios de um objetivo socioeconômico digno, um espaço não-formal de educação bem aproveitado ou uma empresa proativa. Costa \& Resende (2015) nos mostram que outros aspectos podem interferir no processo como falta de tempo para o emprego de atividades de EA, assim a escolaridade dos trabalhadores. Há, no entanto, a aplicação de treinamentos e comunicação interna feita através de informes em murais - são as formas mais próximas de implementação e divulgação de ações relacionadas a EA (COSTA \& RESENDE, 2015).

O quadro se fecha no trabalho realizado por Mendonça \& Colesanti (2015). O retrato geral da população realizado em Uberlândia (MG) pode ser uma simplificação do quadro geral que se verifica nas empresas e estudos de caso. A constatação de que os programas de EA são descontínuos, pontuais e com ausência de projetos vinculados a outros programas não é algo único neste estudo (TOZZONI-REIS, 2001; QUINTAS, 2004). Uma informação interessante é: $45 \%$ atribui a responsabilidade ambiental a terceiros; menos de 20\% já participou de algum evento de educação ambiental (MENDONÇA \& COLESANTI, 2015). É um quadro de inércia demonstrado pela população, o que é um fruto e ao mesmo tempo retroalimenta o distanciamento de sociedade e ambiente.

O perfil do empresariado majoritariamente amostrado também aponta para carência no emprego de práticas de EA. Como mencionam Mendonça \& Colesanti (2015), o licenciamento ambiental é uma ferramenta de controle e monitoramento. A Política Nacional de Educação Ambiental, por outro lado, traz o licenciamento ambiental como forma de implementação de projetos de Educação (BRASIL, 1999). Teoricamente, ambos estão entrelaçados. Entretanto, o conteúdo amostrado indica que a EA não permeia efetivamente as políticas empresariais de modo geral.

Esta questão multifacetada e extremamente complexa que envolve 0 próprio entendimento de EA, suas aplicações e finalidades apresenta muitas 
formas de inovações. O quadro geral apresentado é de uma tomada de consciência que caminha para uma crescente formalização e ganho de força (REIGOTA, 2007; OLIVEIRA, 2010; TORRES et al., 2014); interpretações inovadoras de legislações já vigentes (REIGOTA, 2012; DIAS et al., 2016); instrumentos mercadológicos, valorizados por e através do cidadão e o empresário engajados e conscientes.

\section{CONCLUSÃO}

Inicialmente, aponta-se para o fato de que a variedade de artigos coincide com aspectos realistas do que vem sendo feito em EA, de como a mesma é tratada nos espaços não-formais de educação e nas empresas. Há uma maioria de profissionais que interpretam e empregam a EA voltada ao conhecimento técnico e que visa às atitudes, procedimentos e métodos baseando-se no aspecto científico e econômico.

Apesar de seu valor para fins de preservação ambiental e melhoria de processos, destaca-se que sem um trabalho voltado ao aspecto social, sem a preocupação em contextualizar as práticas na realidade das comunidades envolvidas com os impactos e/ou os trabalhadores que de fato executam os processos, a EA deixa de explorar seu potencial. Em outras palavras, sem a real compreensão das motivações por trás das técnicas e comportamentos adequados, os funcionários envolvidos com as práticas de EA podem não atribuir crédito aos procedimentos; a população de forma similar ao deixar de trabalhar o entendimento das causas dos problemas ambientais, necessidades dos modelos de consumo e econômicos, dos reais problemas que enfrentam e a que estão sujeitos como afetados de instalações e funcionamento de empresas, também tendem a não usufruir da potencial aplicação de EA em suas vidas.

Vários autores vêm indicando de diferentes maneiras estas questões, incluindo alguns estudos enquadrados neste trabalho. Por outro lado, 0 pequeno recorte aqui presente também demonstra largamente o outro lado da 
história, com exemplos práticos de estudos de caso: a forma vigente de como a EA é tratada de forma acrítica.

Os espaços não-formais de educação não foram tão explorados quanto a discussão teórica e prática de interpretações de EA em si, no entanto nota-se que os espaços sugeridos são variados: desde áreas externas até espaços de convívio comum dentro de empresas, incluindo também possibilidades em espaços formais de educação. A diversidade de espaços não-formais de educação recebeu menos destaque devido também a forma como a EA é tratada na maioria dos casos estudados, visto que a distribuição de panfletos, palestras acerca de técnicas e métodos, treinamentos não demandam diversidade estrutural - algo quiçá atrelado a forma acrítica de abordagem.

Um aspecto indicado também de forma conclusiva é que a mentalidade e as práticas voltadas a EA não permeiam o espaço empresarial em grandes proporções, visto que empresas não aplicam, outras fazem eventos pontuais e esporádicos; quando aplicada, a EA tende a ser superficial, apesar de verificarmos exemplos de emprego de práticas mais aprofundadas.

Em suma, há dificuldade e inércia para implementação de mudanças e da própria interpretação dos aspectos sociais e ambiental vinculados ao econômico, aparentemente fruto de uma longa trajetória de compartimentalização destas esferas. A legislação, em tese, permite amplas interpretações que podem divergir em todas as aplicações de EA, permitindo que se edifiquem metodologias críticas e tecnicistas e ao mesmo tempo exista total conformidade legal.

A formação de agentes ambientais em trabalhos com objetos de pesquisa e/ou conceitos trabalhados pelos autores, em espaços não-formais, é algo que não foi amplamente atingido dentro dos preceitos: postura crítica, atividades frequentes e diversidade de locais para implementação. No entanto, o trabalho com Educação Ambiental por si representa uma visibilidade válida como ponto de partida para amadurecimento.

Nota-se uma deficiência na aplicação de práticas em EA, deixando a formação de agentes ambientais nos diferentes cenários já defasada. Se levarmos em consideração o ideário de uma vertente crítica, atividades 
frequentes e lugares diversificados, temos que este viés é uma notável exceção.

Cabe, em última análise, aos cidadãos tomarem consciência do quadro maior dos problemas que os envolvem, ao passo de que cabe aos empreendedores (tanto por necessidades mercadológicas e/ou legais) aplicar de forma ética a EA em suas atividades e processos de licenciamento ambiental; evidente que todo este processo é complexo e também está atrelado aos pesquisadores, intelectuais que continuarão se dedicando ao tema e desta forma promover a pavimentação de um caminho mais seguro a ser trilhado.

\section{REFERÊNCIAS BIBLIOGRÁFICAS}

ALVEZ-MAZZOTTI, Alda Judith; GEWANDSZNAJDER, Fernando. O método nas ciências naturais e sociais: pesquisas quantitativas e qualitativas: São Paulo. Editora Pioneira (2 ${ }^{\underline{a}}$ reimpressão). 203p. 1999.

BAGNOLO, Carolina Messora. "Empresariado e ambiente: algumas considerações sobre a Educação Ambiental no espaço escolar". Ciência \& Educação. v. 16, n. 2, p 401-413. 2010.

BRASIL, 1981. Lei no 6.938, de 31 de agosto de 1981. Dispõe sobre a Política Nacional do Meio Ambiente, seus fins e mecanismos de formulação e aplicação, e dá outras providências. Brasil. 1981.

BRASIL, 1988. Constituição da República Federativa do Brasil, de 05 de outubro de 1988. Brasil. 1988.

BRASIL, 1999. Lei no 9.795, de 27 de abril de 1999. Dispõe sobre a educação ambiental, institui a Política Nacional de Educação Ambiental e dá outras providências. Brasil. 1999.

BRASIL, 2002. Decreto o 4.281, de 25 de junho de 2002. Regulamenta a Lei no 9.795, de 27 de abril de 1999, que institui a Política Nacional de Educação Ambiental, e dá outras providências. Brasil. 2002.

BRASIL, 2010. Lei o 12.305, de 2 de agosto de 2010. Institui a Política Nacional de Resíduos Sólidos; altera a Lei oㅜ 9.605, de 12 de fevereiro de 1998; e dá outras providências. Brasil. 2010.

BRASIL, 2012. Resolução ME no 2, de 15 de junho de 2012. Estabelece as Diretrizes Curriculares Nacionais para a Educação Ambiental. Brasil .2012. 
CARVALHO, Isabel Cristina de Moura. Em direção ao mundo da vida: interdisciplinaridade e educação ambiental. Brasília: Cadernos de educação ambiental. IPÊ: Instituto de Pesquisas Ecológicas. 1998.

CASSOL, Alessandra; CINTRA, Renato Fabiano; LUZ, Josiane. "A responsabilidade social corporativa e as práticas de gestão do capital intelectual divulgadas por empresas do setor de papel e celulose". Journal of Environmental Management and Sustainability. v. 6. n. 3. p. 1-13. 2017.

COSTA, José Marcione; REZENDE, Júlio Francisco Dantas. "Aprendizagem organizacional e sustentabilidade ambiental: um estudo com as empresas associadas à REDEPETRO-RN". Revista Eletrônica Gestão e Sociedade. v. 9. n. 24. p. 1098-1127. 2015.

DIAS, Leonice Seolin; LEAL, Antonio Cezar; JUNIOR, Salvador Carpi. Educação Ambiental: conceitos, metodologias e práticas. Tupã, São Paulo: ANAP - Associação Amigos da Natureza da Alta Paulista. 190p. 2016.

FARIA, Jeniffer de Souza; PINTO, Vicente Paulo dos Santos. "A Educação Ambiental no licenciamento ambiental: reflexões teóricas e metodológicas pertinentes". Educação Ambiental em Ação. p. 1-9. 2018.

FREIRE, Paulo. Pedagogia do oprimido. Rio de Janeiro: Paz e Terra. 213p. 2005.

FRIGO, Juliana Pires; SILVEIRA, Djalma Silva. "Educação Ambiental e construção civil: práticas de gestão de resíduos em Foz do Iguaçu-PR". Monografias Ambientais REMOA/UFSM. v. 9 n. 9. p. 1938-1952. 2012.

GOHN, Maria da Glória. "Educação não-formal, participação da sociedade civil e estruturas colegiadas nas escolas". Rio de Janeiro: Ensaio: avaliação das políticas públicas em Educação. v. 14, n. 50, p. 27-38. 2006.

GOHN, Maria da Glória. "Educação não-formal, educador(a) social e projetos sociais de inclusão social". Rio de Janeiro: Meta: avaliação. v. 1, n. 1, p. 28-43. 2009.

JACOBI, Pedro Roberto. "Educação Ambiental, cidadania e sustentabilidade". Cadernos de Pesquisa (USP). n. 118. p. 189-205. 2003

JACOBI, Pedro Roberto.; TRISTÃO, Martha; FRANCO, Maria Isabel Gonçalves Correa. "A função social da Educação Ambiental nas práticas colaborativas: participação e engajamento". Campinas: Centro de Estudos Educação e Sociedade. v. 29. n. 77. p. 63-79. 2009.

KONFLANZ, Tais; FREITAS, Núbia. "A Educação Ambiental inserida no licenciamento". Santa Maria: Monografias Ambientais REMOA/UFSM. p.180187. 2015. 
MACHADO, Sânia Morena Freire; LOUREIRO, Cleberley; LEITE, Rosiane Resende; BRITO, Tiago Silva Alves.; VASCONCELOS, Fernanda Carla Wasner. "Educação Ambiental no processo de licenciamento". Educação Ambiental em Ação. p. 1-9. 2018.

MENDONÇA, Mauro das Graças; COLESANTI, Marlene Teresinha de Muno. "Reflexões sobre teoria e prática em Educação Ambiental: estudo de caso da percepção ambiental da população do município de Uberlândia (MG)". Caminhos de Geografia. v. 16. n. 56. p. 185-206. 2015.

MORAIS, Caroline Ferreira; COLESANTI, Marlene Teresinha de Muno. "Uma proposta para coleta seletiva: implantando a Educação Ambiental na empresa Schincariol - Uberlândia/MG". Caminhos de Geografia. v.12. n. 38. p. 221-236. 2011.

NETO, Geraldo Cardoso de Oliveira; FILHO, Moacir Godinho; GANGA, Gilberto Miller Devós; NAAS, Irenilza Alencar; VENDRAMETTO, Oduvaldo. "Princípios e ferramentas da produção mais limpa: um estudo exploratório em empresas brasileiras". São Carlos: Gestão e Produção. v. 22. n. 2. p. 326-344. 2015.

NEVES, Eduardo Borba; PICONCELLI, Maressa Cristina Almeida; OLIVEIRA, Sophia Hideko Kohata; ROZEMBERG, Brani. "Práticas de Educação Ambiental: breve diagnóstico em organizações militares do Exército Brasileiro". Ciência e Educação. v. 18. n. 1. p. 173-186. 2012.

OLIVEIRA, Elísio Márcio. Cidadania e educação ambiental: uma proposta de educação no processo de gestão ambiental. Brasília: Ministério do Meio Ambiente, Instituto Brasileiro do Meio Ambiente e dos Recursos Naturais Renováveis. 232p. 2010.

QUINTAS, José Silva. Educação no processo de gestão ambiental: uma proposta de educação ambiental transformadora e emancipatória. In: Identidades da Educação Ambiental Brasileira. Philippe Pomier Layrargues (coord.). Brasília: Ministério do Meio Ambiente. p. 113-140. 2004.

REIGOTA, Marcos Antonio dos Santos. "Ciência e sustentabilidade: a contribuição da educação ambiental". Revista de Avaliação da Educação Superior. v. 12. n. 2. 219-232. 2007.

REIGOTA, Marcos Antonio dos Santos. "Educação Ambiental: a emergência de um campo científico". Florianópolis: Perspectiva. v. 30. n. 2. p 499-520. 2012.

RODRIGUES, Jéssica do Nascimento; OLIVEIRA, Aline Lima; QUEIROZ, Edileuza Dias. "Universidade e formação de educadores ambientais críticos". Rio Claro: Educação: teoria e prática. v. 23, n. 42, p. 90-105. 2013.

RODRIGUES, Ana Raquel de Souza. "Educação Ambiental em tempos de transição paradigmática: entrelaçando saberes "disciplinados". Bauru: Ciência e Educação. v. 20. n. 1. p. 195-206. 2014. 
SILVA, Vanderlei Aparecido; JESUS, Marcos Junio Ferreira; MORIGI, Josimari de Brito; SOUZA, Adalberto Dias. "Práticas de sustentabilidade na gestão da empresa Cristófoli Equipamentos de Biossegurança, situada no município de Campo Mourão, Paraná, Brasil". Joçaba: Revista de Administração, Contabilidade e Economia. v. 14. n. 2. p. 479-504. 2015.

TIBÚRCIO, Gabriela Santos; LOGAREZZI, Amadeu José Montagnini. "Interdisciplinaridade e educação ambiental no Pibid: diálogos entre sujeitos no contexto de múltiplas disciplinas e múltiplos saberes". Rio Grande: Revista Eletrônica de Mestrado em Educação Ambiental. v. 34, n. 2, p. 318-339. 2017.

TORRES, Juliana Rezende; FERRARI, Nadir; MAESTRELLI, Sylvia Regina Pedrosa. Educação ambiental crítico-transformadora no contexto escolar: teoria e prática freireana. In: Educação ambiental: dialogando com Paulo Freire. Carlos Frederico B. Loureiro e Juliana Rezende Torres (orgs.). São Paulo: Cortez Editora. 184p. 2014.

TOZZONI-REIS, Marília Freitas de Campos. "Educação ambiental: referências teóricas no ensino superior". Interface Comunicação, Saúde, Educação. v. 5, n. 9, p. 33-50. 2001.

TOZZONI-REIS, Marília Freitas de Campos. "Formação dos educadores ambientais e paradigmas em transição". Ciência \& Educação. v. 8, n. 1, p. 8396. 2002. 